\title{
Enabler for success in information technology implementation: a case discussion of telemedicine of Odisha
}

\section{Debendra Kumar Mahalik}

P.G. Department of Business Administration, Sambalpur University,

Odisha, India

Email: debendra_mahalik@hotmail.com

\begin{abstract}
In the global market, computer and information technology advancement is growing rapidly and so also its applications and the government sector are no exception to it. Use of information and technology is the one way to bridge the shortage of resources to the customers at large. Literatures reveal that the success rates of these projects are less due to various reasons. So the researchers are trying to find out the enablers for the success of these projects so that its due importance can be given, which will facilitate the implementation and improve the success rate. Literatures also reveal if these enablers could be found, then the managers can give its due importance, which will facilitate the implementation and improve the success rate. In this paper, attempt has been made to find out various enabler using interpretive structural modelling (ISM) and their interrelationship and its impact for success of these projects using a case of telemedicine, which is presently implemented in Odisha.
\end{abstract}

Keywords: telemedicine; IT-enablers; interpretive structural modelling; ISM.

Reference to this paper should be made as follows: Mahalik, D.K. (2017) 'Enabler for success in information technology implementation: a case discussion of telemedicine of Odisha', Int. J. Telemedicine and Clinical Practices, Vol. 2, No. 1, pp.12-30.

Biographical notes: Debendra Kumar Mahalik is currently working as a reader at the PG Department of Business Administration, Sambalpur University. He has around 15 years of teaching and six years of industry experience. $\mathrm{He}$ received his $\mathrm{PhD}$ in the area of IT-enabled supply chain management. He has published around 30 papers in international and national journals and conference proceedings. His areas of interest include application of information technology in business, efficiency analysis and multi-criteria decision making.

This paper is a revised and expanded version of a paper entitled 'Enabler for success in information technology implementation' presented at A Case Discussion of Telemedicine of Odisha, ORSI, Conference 2014, Tirupati, India 1-4 December 2014. 


\section{Introduction}

Today's competitive information technologies (IT) environment have already proven to be a tool to bring effectiveness in the business from transaction to data processing and healthcare facilities are not an exception to it. With this aspect, telemedicine is the use of ICT technology to transmit and receive medical information and facilitate the patient from a remote location. At the same time with the stabilisation of the technological backbone whereby almost all media content - image, videos, sound, text - can be transmitted and acted upon in real time, telemedicine is emerging as the frontier for ensuring the inclusiveness of quality healthcare services to the entire population base (http://ehealth.eletsonline.com). However, the working definition of telemedicine varies from 'medical care and health supporting practices based on patient information derived from images transmitted from a remote site'. Several benefit forced the government to adopt this new technology. Some of them are to improve the efficiency of medical care, to improve service for patients and physicians, to deliver medical care to patients in places where medical care is not otherwise accessible. So it has been proved that telemedicine is one of the methods to increase effectiveness of medical services. Witnessing these benefits, many of the governments has adopted this services and India is no exception to it.

As India is a developing country with respect to economic, it is also growing its health expenditure on infrastructures and awareness of health. But there is still much to be done as there is a shortage of doctors or physicians and infrastructure. According to Odisha Trust for Technical Education and Training (OTTET), the state of Odisha has almost 40 million people. Telemedicine activities in Odisha initiated in 2001 with the support from Department of Information Technology, Government of India, Sanjay Gandhi Post Graduate Institute of Medical Sciences, Lucknow, Indian Space Research Organization (ISRO), and Department of Space, Government of India. Odisha Telemedicine Network (OTN) was developed in three phases as described below. The state of Odisha is the first in the country to have all its district hospitals linked to the medical colleges and super specialty hospitals under OTN. Apart from the infrastructure various others factors are also responsible to increase the effectiveness of the system. As per OTTET data, physicians are at one per 1,000 people, nurses are at 0.8 per 1,000 people and care facilities are at one bed per 1,000 people in India. India needs to build at least 750 hospitals of 250 beds each, every year, to achieve the minimum national health standards stipulated by the World Health Organization. India, where $70 \%$ of the people are residing in rural also restricts these services to be widely available, since most of the healthcare facilities are located in the urban area. Therefore the gap between demands versus supply is widening. So information technology is the one way to lowering this gap. Hence telemedicine is applied everywhere in India among which Odisha is one of the primary concern. The government has invested huge money to develop the necessary infrastructure for the telemedicine; still the effectiveness of the system has not been improved much. So there is a need to study factors responsible for success. With this, the objective of the present study is to identify enablers for success in implementing information technology in telemedicine and to show their interrelationship by digraph and hierarchical model. 


\section{Literature review}

Today's competitive environment information technologies (ITs) have already proved to be a tool to bring effectiveness in the business from transaction to data processing and health care facilities are not exception to it. With Sharma et al. (2014), these data have been collected from various sources and are attracting more analysis leading to development of models. The data are structured, unstructured, and heterogeneous, generated from various sources resulted increase in importance, so data science the present day (Sharma et al., 2016). The considerable velocity of the volume expansion of the data possesses the serious challenges for the existing data processing systems. Various authors have discussed various modern data models that process the extremely large data such as Big Data in an effective way. Healthcare are not exception to big data it providers in various information based on data. These data can reveal effectiveness of the system. These data can reveal the effectiveness of the system. The health sector across the globe is facing various challenges, for example, Malaysia is facing the challenges linking clinical administrative processes to ensure that an effective collaboration and efficient delivery of care are in place (Ratnam and Dominic, 2016). So researchers are trying to find the factors associated for improving effectiveness of the overall system. Recently, various alternative like cloud computing offers an alternative to traditional technology with reducing cost on powerful computing and effective performance (El and Monir, 2016). The public and private clouds are characterised by flexibility and operational efficiency that reduces costs and improve performance. Simultaneous numerous statistical methods have been developed over the recent years to justify and measure these investments. Various models and comparative evaluations of these models are also proposed in literature (Bouwmans, 2011). In this paper we are trying to find out various enablers through secondary sources through structured questionnaire and enablers were checked for relevance using interpretive structural modelling (ISM).

ISM was initially introduced by Warfield in 1973. Warfield (1976) has developed a concrete and powerful methodology for analysing complex variables. ISM can be applied to the systematic application of some elementary notions of graph theory and Boolean algebra in such a way that theoretical, conceptual, and computational leverage is exploited to efficiently construct a directed graph, or network representation, of the complex pattern of a contextual relationship among a set of elements (David, 1975). Rajesh et al. (2013) have described the definitions and few steps involved in ISM modelling which are as follows:

1 Identify the enablers or elements which are relevant to the problem. This could be done by a survey, expert opinion or group problem solving technique.

2 Establish a contextual relationship between enablers.

3 Formation of structural self-interaction matrix (SSIM) enablers to suggest the pair-wise relationship among enablers of the problem. Transitivity rule is applied then.

4 Create a reachability matrix from the SSIM.

5 Partition the reachability matrix into different levels.

6 Draw digraph based on the relationship given in reachability matrix. 
7 Form an ISM-based multileveled hierarchical model by replacing element nodes with the statements.

ISM can be applied to solve various complex and subjective problems in the real world application (Jayant et al., 2014). Their literature reveals application in supply chain system and very few in other areas. Rajesh et al. (2013) used the ISM methodology to determine the enablers in the implementation of total productive maintenance (TPM). He has identified ten enablers and developed a model to find out the most important enabler in implementing the TPM by using ISM technique. Adel and Karim (2013) have applied the ISM technology to design a model by analysing the dimensions and indicators of business orientations. Kumar et al. (2013) have applied ISM technique to find out the most important enablers and their mutual relationships in improving the agri-based economy by giving focus to supply-chain systems. They identified ten enablers and developed a hierarchical model among themselves and their driving power and dependency of enablers. Attri et al. (2013) have used ISM technique to find out the enablers and their mutual relationship for the implementation of TPM. Attri et al. (2012) have applied ISM approach to know the barriers and their behaviour in the implementation of TPM. Raj et al. (2012) have implemented ISM methods and its steps in flexible manufacturing system to describe the flexibility of factors from the contextual relationship amongst those factors. Jitesh et al. (2008) have applied ISM technique to identify key enabler for Indian manufacturing SMEs. Thakkar et al. (2008) have utilised ISM approach for evaluating and comparing supply chain relationships, specifically when, small and medium scale enterprise (SME) is considered as focal company. Thakkar et al. (2007) have applied ISM approach to develop the balanced scorecard (BSC) for a real life case company KVIC (Khadi and Village Industries Commission, organic food sector, India) with qualitative and quantitative analysis. Qureshi et al. (2007) utilised this technique to compare and develop the relation between shippers and logistics service providers (LSPs) to measure the effect of productivity and competitiveness of the shipper company. Faisal et al. (2007) applied this technique in supply chain risk mitigation to identify various information risks that could impact a supply chain, and developed a conceptual framework to quantify and mitigate them. Singh et al. (2007) have used this technique to identify and develop the structural relationship among different factors for successful implementation of AMTs. Faisal et al. (2006) have applied this technique in supply chain risk mitigation by finding out enablers. Agarwal et al. (2006) have applied this technique for identifying direct and indirect relationship among the variables so that they can develop a proposed framework for agility improvement of case supply chain. Bolanos et al. (2005) have implemented this analysis for making functional and better decision among executives of different functional areas. Ravi et al. (2005) have applied ISM technique in computer hardware supply chain system for finding the primary reverse logistics variables, so that manager can improve the performance of computers and their productivity. Jharkharia and Shankar (2004) utilised this technique to find out the key enablers and their comparisons which affects the IT enablement of supply chain. Singh et al. (2003) have implemented this methodology in the educational system for management in engineering industries. Sharma et al. (1995) designed a hierarchy of actions by ISM analysis required to achieve the future objectives of waste management in India. Mandal and Deshmukh (1994) have used ISM analysis to calculate the driving power and dependence of different vendor selection criteria as the factors and their inter-relationship. Saxena et al. (1992) have used 
this technique with some consideration of fuzzy logic for to develop a hierarchical level of the variables and to recognise which one is the key variable for their energy conservation system in the Indian cement industry. Saxena et al. (1990) have analysed the variables by using the ISM methodology in their case study 'Energy conservation in the Indian cement industry'. They have provided the direct or indirect relations between those variables.

The ISM technique is used for finding out suitable relationships among the identified enablers for IT applications like e-health, telemedicine. ISM is one strong methodology to analyse qualitative factors and give their mutual relationships. It gives the driving power and dependence of factors so that it inter relates to each other with hierarchical model. Some of the author discussed similar problem from a social angle $\mathrm{Hu}$ et al., 2013). In our study we encountered various enablers which effects the success of telemedicine network in Odisha. ISM has advantage to represent the original problem in a graphical format and in to a structure model has can be communicated more effectively to others Author (George and Pramo, 2014). He also reveal that the process efficiency depend on the use and context of transitive inference, which reduce the number of required queries by $50 \%$ to $80 \%$, is a learning tool by forcing participants to develop a deeper understanding of the meaning and significance of a specified element. IT helps policy maker to list and to establish relation, by assisting participants in identifying particular areas for policy action which offer advantages or leverage in pursuing specified objectives. ISM systematizes the process by considering all possible pair wise relations of system elements, either directly from the responses of the participants or by transitive inference, also helps the quality of interdisciplinary and interpersonal communication within the context of the problem situation by focusing the attention of the participants on one specific question at a time. It also encourages issue analysis by allowing participants to explore the adequacy of a proposed list of systems elements or issue statements for illuminating a specified situation, it does not require knowledge of the underlying process is required of the participants; they simply must possess enough understanding of the object system to be able to respond to the series of relational queries generated by the computer. It guides and records the results of group deliberations on complex issues in an efficient and systematic manner (Watson, 1978).

\subsection{Limitations of ISM approach}

Presence of large no of variable increases the complexity of ISM methodology and with limited numbers of variable the model development becomes easy. In order to reduce variables, least affecting a variables problem or issue may not be taken in the development of ISM model. Experts help are only taken in analysing the driving and dependence power of the variable of a problem or issue. These models are not statistically validated. Structural equation modelling (SEM), also commonly known as linear structural relationship approach, has the capability of testing the validity of such hypothetical model (George and Pramod, 2014).

\section{Case analysis}

As per recent report on Telemedicine's Impact on Healthcare Cost and Quality in April 2015, by American Telemedicine Association (ATA), 40 years of research has yielded a 
wealth of data about the cost effectiveness and efficacy of many telemedicine applications. Various publications like PubMed, a bibliographic database of medical research that is maintained by the National Library of Medicine includes over 12,000 citations of published works related to telemedicine. Various studies been carried above the cost effectiveness of the system, quality of care and patient acceptance of telemedicine. In addition, leading, validated studies have been identified by many of the ATA member groups. Very little research had been done to study on the factors for improving the effectiveness of the system. IT enablers are factors which improves the applications of information technology. In our case analysis, we have indentified 12 enablers for telemedicine project. These factors are considered after taking feedback from experts working in telemedicine units like staffs, patients and doctors of the primary telemedicine unit of Odisha, i.e. SCB Medical College, Cuttack and VSS Medical College, Burla, which is the central hub and connects rural areas like Bhawanipatna (Kalahandi), Sambalpur telemedicine units and other units across the state of Odisha. IT enabler's factors are as below:

1 Cost factor: As like any other system telemedicine also needs finance to support and maintain its components like equipment, staff etc.

2 Connectivity: Telemedicine is an electronic transmission of medical information; it requires a well established and high speed network to connect and capable transmitting voice, video, image, graphic etc.

3 Power supply: Similar to connectivity, a stabilised power supply is required to make operational all of the equipments.

4 Infrastructure and technology: Telemedicine requires high end server and related equipment for its operations.

5 Doctor: Above all expert doctors and paramedical staff are needed to be consulted over the network for expert advice.

6 Skilled manpower: Skilled manpower is required for operation and maintenance of the system.

7 Sophistication of technology: Not only manpower or accessories are important but side by side the technology should be easy to use for all of them. All staff of telemedicine unit can handle the equipment and they should know the technology very well to operate at extremes. This is one more important factor responsible for success in the IT implementation in telemedicine.

8 Proper management staff: To manage the operation, efficient management supervision is a must for smooth operation of the system.

9 Lab facility and medicine at remote area: Telemedicine does not only require transmission of information and expert advice, but also lab facility and availability of medicine are needed for the well being of the patients.

10 Convenient and effective work environment: Convenient and effective work environment is one of the motivations for the staff for better operations. 
11 Support from government: Since telemedicine is established by the government, so their financial and other administrative supports are a must for success of these projects.

12 Public awareness: Public awareness is one of the success factors to increase the effectiveness of the system.

Apart from the above literature reveals many concepts of telemedicine and e-health across the world, which improves the health condition in remote areas through better consultation, which was otherwise not accessible in the traditional setup.

\section{Analysis}

In our study, we have used ISM as a tool for further analysis. We have presented descriptive statistics to rank these enablers accordingly on the basis of mean score and standard deviation as shown in Table 1. Further, Pearson's bi-variate two-tailed correlation test is calculated to check the existence of any multi-collinearity, which is .9 or above indicated in Table 2. The result indicates that the correlations among 12 enablers is high and have no such evidence of multi-collinearity.

Further analysis was carried out using ISM technique, using 12 enablers. These processes are discussed in various stages in detailed form of developing an ISM model as well as digraph for the enablers. Formation of SSIM is an ISM methodology, which was used for finding the contextual relationship among the identified enablers using expert's opinion represented in Table 3. They will find out pair-wise relationships. These relationships were identified by using four symbols (V, A, X and O) by comparing between enablers $i$ and $j$ respectively: where $\mathrm{V}$ represents enabler $i$ will support enabler $j$; A represents enabler $j$ will support enabler I; X represents that both enabler $i$ and $j$ will support each other; $\mathrm{O}$ represents that enabler $i$ and enabler $j$ are not related to each other. Here value of $i$ and $j$ ranges from $1,2 \ldots 12$.

\subsection{Reachability matrix}

Initially reachability matrix which is in binary form, that is, $1 \mathrm{~s}$ and $0 \mathrm{~s}$ followed by certain rules is obtained from our pair-wise relationship of the enablers in SSIM (see Table 3). The rules which are followed are explained below:

- $\quad$ if $(i, j)$ entry in SSIM is $\mathrm{V}$, then in the initial reachability matrix $(i, j)$ entry $=1$ and $(j, i)$ entry $=0$

- $\quad$ if $(i, j)$ entry in SSIM is A, then in the initial reachability matrix $(i, j)$ entry $=0$ and $(j, i)$ entry $=1$

- $\quad$ if $(i, j)$ entry in SSIM is X, then in the initial reachability matrix $(i, j)$ entry $=1$ and $(j, i)$ entry $=1$

- if $(i, j)$ entry in SSIM is $\mathrm{O}$, then in the initial reachability matrix $(i, j)$ entry $=0$ and $(j, i)$ entry $=0$. 
Table 1 Ranking the enabler

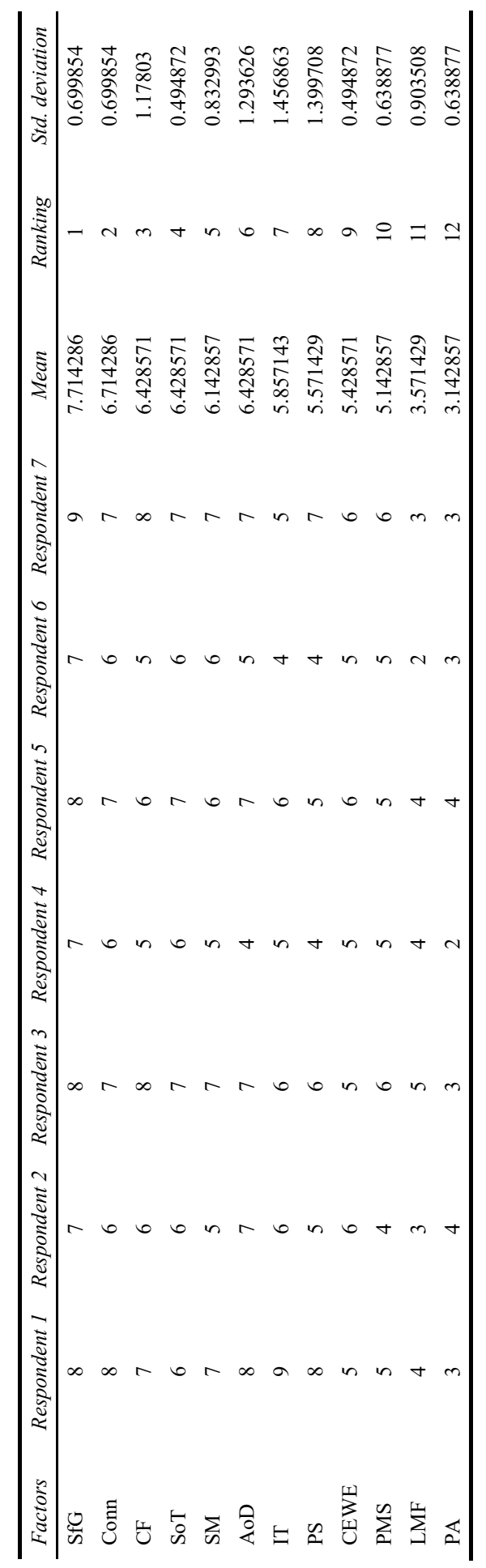


Table 2 Correlation coefficients for enablers

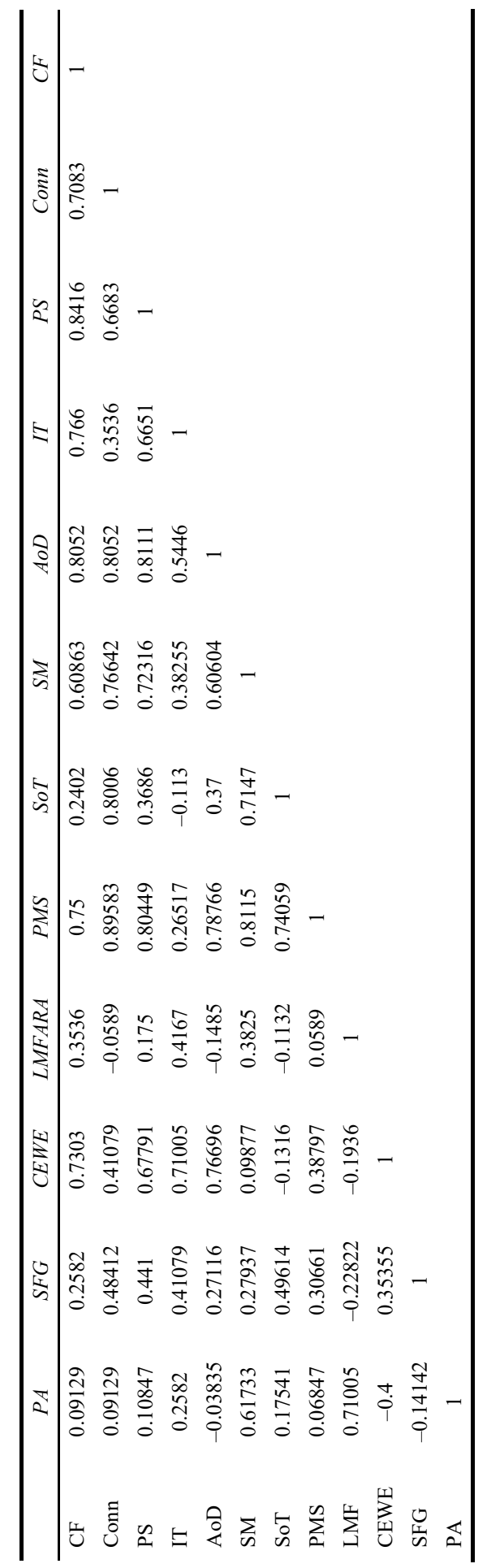


Table 3 Structural self-interaction matrix

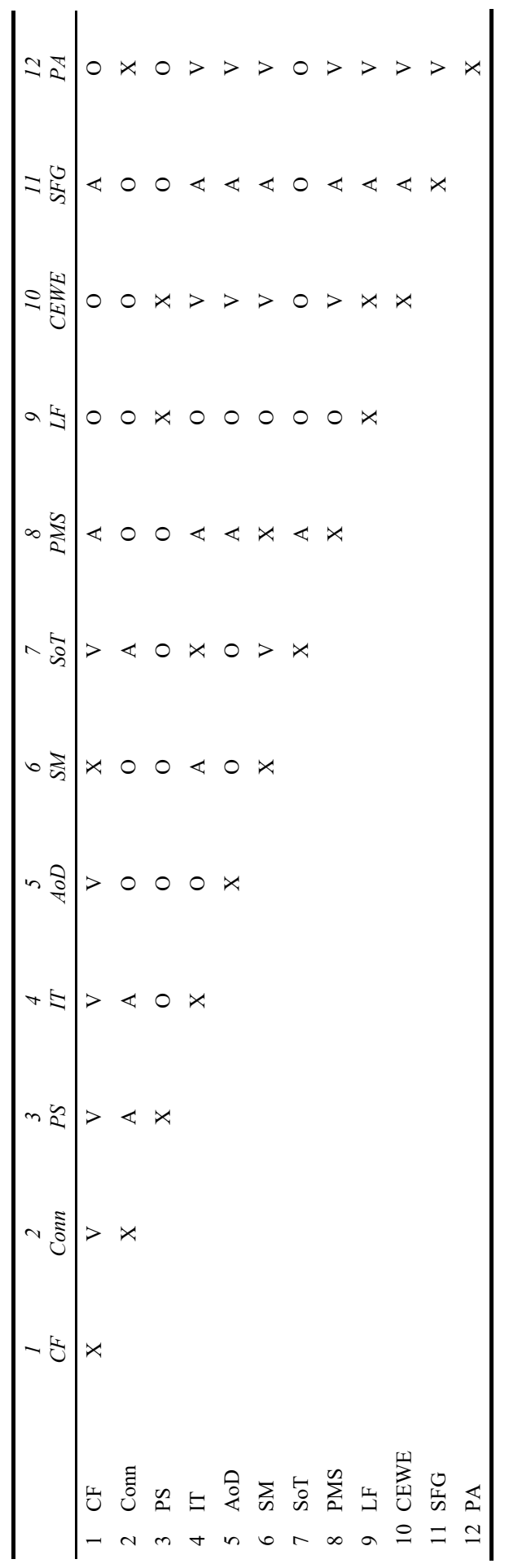


Table 4 Initial reachability matrix

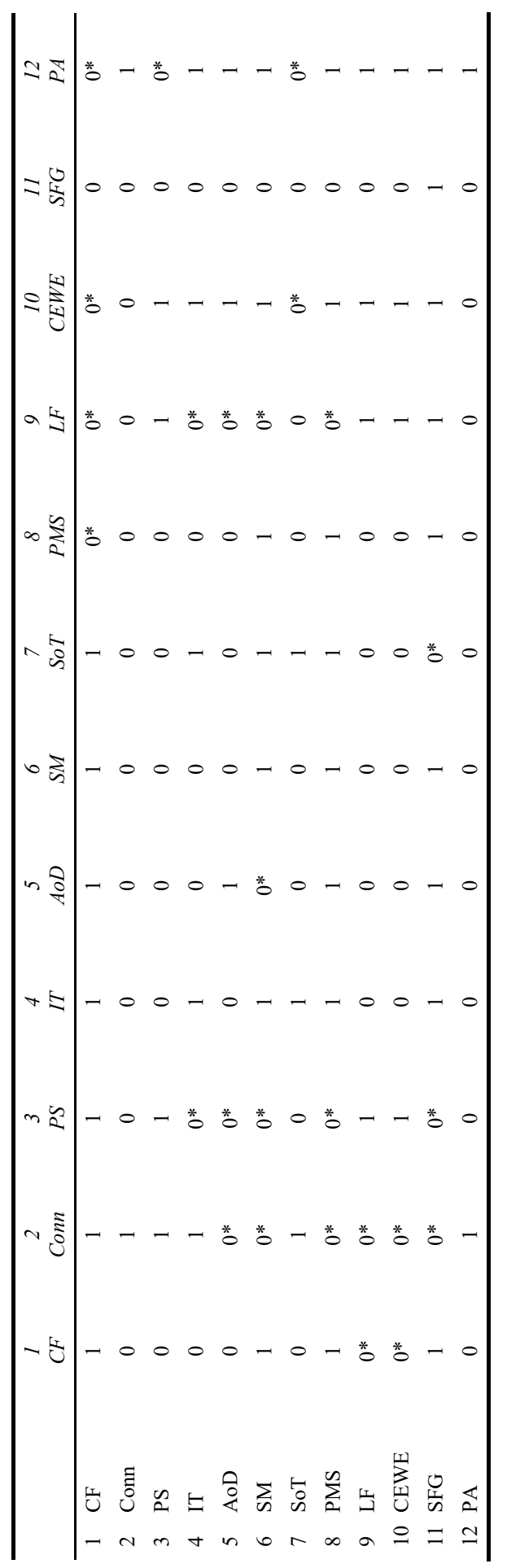


Table 5 Final reachability matrix

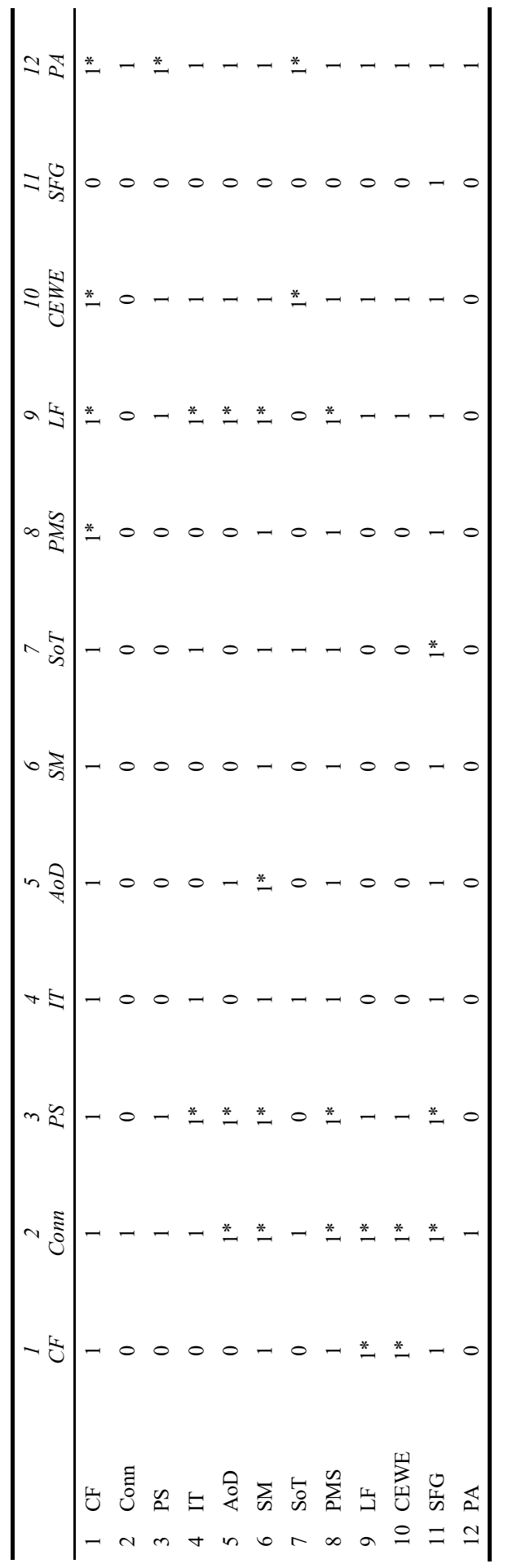


Table 6 Driving power and dependence calculation

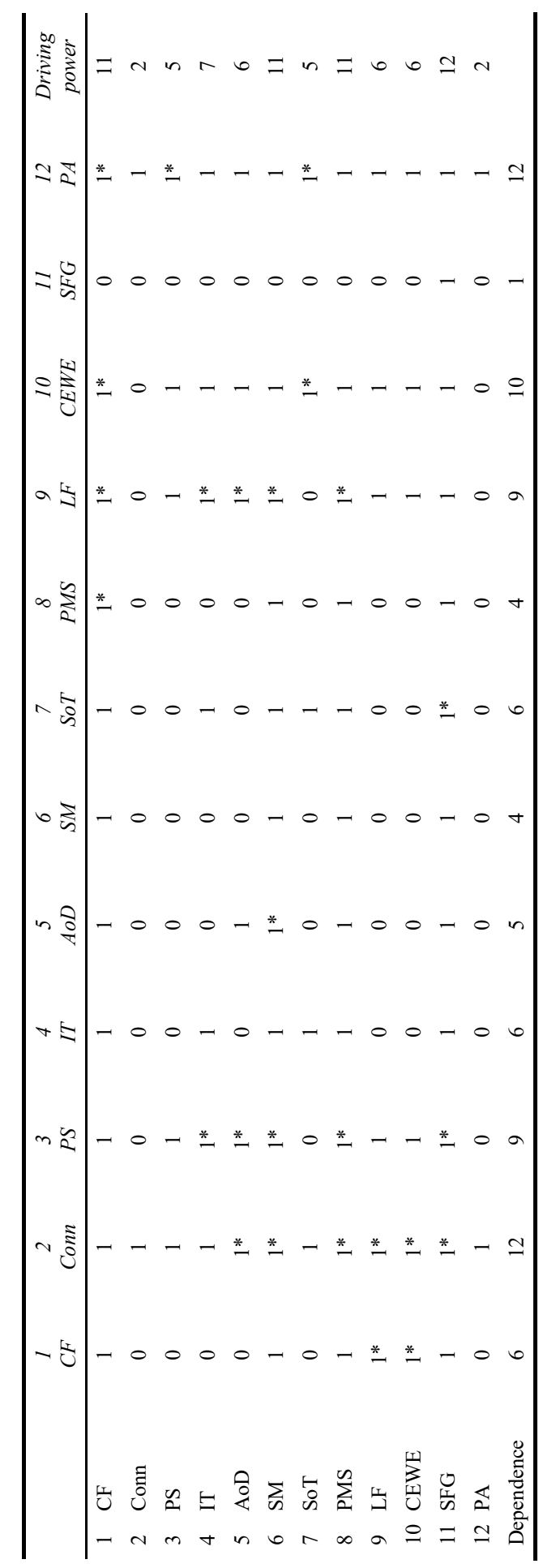


Therefore, by applying the above rule, initial reachability matrix for the identified enablers is shown in Table 4. It is always true that enabler has an effect on itself. One basic assumption in ISM methodology is that to apply the concept of transitivity rule. The transitivity rule says that if $A$ is in relation with $B$, and $B$ is in relation with $C$, then $A$ must be related to $\mathrm{C}$. By applying this property, our final reachability matrix (see Table 5) is obtained. In Table 5, * indicates that the transitivity rule is applied to that cell. From this final reachability matrix, we can find out the driving power and dependence of each enabler by adding them horizontally and vertically respectively (see Table 6).

\subsection{Level partitions using iteration method}

From the final reachability matrix, the reachability set $(R)$ and antecedent set $(C)$ are explored for all basic identified enablers. The reachability set $(\mathrm{R})$ consists of the enablers itself and others as well, which it will support, whereas the antecedent set (C) consists of the enablers itself and others as well, which will help in supporting it. Then the intersection of these sets, that is, $\mathrm{R}$ and $\mathrm{C}$ is derived for all enablers from the iteration method as shown in Table 7. From this table, the enablers which are the same for reachability set $(\mathrm{R})$ and intersection set of $\mathrm{R}$ and $\mathrm{C}$ are selected to define the levels for building the final ISM hierarchy structured model. The identified enablers are partitioned into six levels as obtained from the result (Table 7).

Table 7 Level of partition using ISM analysis

\begin{tabular}{|c|c|c|c|}
\hline \multicolumn{4}{|c|}{ Level-1 } \\
\hline Factors & Reachability set $(R)$ & Antecedent set $(C)$ & Intersection $\operatorname{set}(R C)$ \\
\hline 1 & $\begin{array}{c}1,2,3,4,5,6,7 \\
\quad 8,9,10,12\end{array}$ & $1,6,8,9,10,11$ & $1,6,8,10$ \\
\hline 2 & 2,12 & $\begin{array}{c}1,2,3,4,5,6,7 \\
8,9,10,11,12\end{array}$ & 2,12 \\
\hline 3 & $2,3,9,10,12$ & $1,3,4,5,6,8,9,10,11$ & $3,9,10$ \\
\hline 4 & $2,3,4,7,9,10,12$ & $1,4,6,7,8,11$ & 4,7 \\
\hline 5 & $2,3,5,9,10,12$ & $1,5,6,8,11$ & 5 \\
\hline 6 & $\begin{array}{l}1,2,3,4,5,6 \\
7,8,9,10,12\end{array}$ & $1,6,8,11$ & $1,6,8$ \\
\hline 7 & $2,4,7,10,12$ & $1,4,6,7,8,11$ & 4,7 \\
\hline 8 & $\begin{array}{l}1,2,3,4,5,6 \\
7,8,9,10,12\end{array}$ & $1,6,8,11$ & $1,6,8$ \\
\hline 9 & $1,2,3,9,10,12$ & $1,3,4,5,6,8,9,10,11$ & $1,3,9,10$ \\
\hline 10 & $1,2,3,9,10,12$ & $1,3,4,5,6,7,8,9,10,11$ & $1,3,9,10$ \\
\hline 11 & $\begin{array}{c}1,2,3,4,5,6,7 \\
8,9,10,11,12\end{array}$ & 11 & 11 \\
\hline 12 & 2,12 & $\begin{array}{c}1,2,3,4,5,6,7 \\
8,9,10,11,12\end{array}$ & 2,12 \\
\hline
\end{tabular}

Notes: $\mathrm{L} 1=\{2,12\} ; \mathrm{L} 2=\{3,9,10\} ; \mathrm{L} 3=\{5\} ; \mathrm{L} 4=\{4,7\} ; \mathrm{L} 5=\{1,6,8\} ; \mathrm{L} 6=\{11\}$. 
Table 7 Level of partition using ISM analysis (continued)

\begin{tabular}{|c|c|c|c|}
\hline \multicolumn{4}{|c|}{ Level-2 } \\
\hline Factors & Reachability set (R) & Antecedent set (C) & Intersection $\operatorname{set}(R C)$ \\
\hline 1 & $1,3,4,5,6,7,8,9,10$ & $1,6,8,9,10,11$ & $1,6,8,10$ \\
\hline 3 & $3,9,10$ & $1,3,4,5,6,8,9,10,11$ & $3,9,10$ \\
\hline 4 & $3,4,7,9,10$ & $1,4,6,7,8,11$ & 4,7 \\
\hline 5 & $3,5,9,10$ & $1,5,6,8,11$ & 5 \\
\hline 6 & $1,3,4,5,6,7,8,9,10$ & $1,6,8,11$ & $1,6,8$ \\
\hline 7 & $4,7,10$ & $1,4,6,7,8,11$ & 4,7 \\
\hline 8 & $1,3,4,5,6,7,8,9,10$ & $1,6,8,11$ & $1,6,8$ \\
\hline 9 & $1,3,9,10$ & $1,3,4,5,6,8,9,10,11$ & $1,3,9,10$ \\
\hline 10 & $1,3,9,10$ & $1,3,4,5,6,7,8,9,10,11$ & $1,3,9,10$ \\
\hline 11 & $1,3,4,5,6,7,8,9,10,11$ & 11 & 11 \\
\hline \multicolumn{4}{|c|}{ Level-3 } \\
\hline Factors & Reachability set $(R)$ & Antecedent set (C) & Intersection set $(R C)$ \\
\hline 1 & $1,4,5,6,7,8$ & $1,6,8,11$ & $1,6,8$ \\
\hline 4 & 4,7 & $1,4,6,7,8,11$ & 4,7 \\
\hline 5 & 5 & $1,5,6,8,11$ & 5 \\
\hline 6 & $1,4,5,6,7,8$ & $1,6,8,11$ & $1,6,8$ \\
\hline 7 & $4,7,10$ & $1,4,6,7,8,11$ & 4,7 \\
\hline 8 & $1,4,5,6,7,8$ & $1,6,8,11$ & $1,6,8$ \\
\hline 11 & $1,4,5,6,7,8,11$ & 11 & 11 \\
\hline \multicolumn{4}{|c|}{ Level-4 } \\
\hline Factors & Reachability set $(R)$ & Antecedent set $(C)$ & Intersection set $(R C)$ \\
\hline 1 & $1,4,6,7,8$ & $1,6,8,11$ & $1,6,8$ \\
\hline 4 & 4,7 & $1,4,6,7,8,11$ & 4,7 \\
\hline 6 & $1,4,6,7,8$ & $1,6,8,11$ & $1,6,8$ \\
\hline 7 & $4,7,10$ & $1,4,6,7,8,11$ & 4,7 \\
\hline 8 & $1,4,6,7,8$ & $1,6,8,11$ & $1,6,8$ \\
\hline 11 & $1,4,6,7,8,11$ & 11 & 11 \\
\hline \multicolumn{4}{|c|}{ Level-5 } \\
\hline Factors & Reachability set $(R)$ & Antecedent set (C) & Intersection $\operatorname{set}(R C)$ \\
\hline 1 & $1,6,8$ & $1,6,8,11$ & $1,6,8$ \\
\hline 6 & $1,6,8$ & $1,6,8,11$ & $1,6,8$ \\
\hline 8 & $1,6,8$ & $1,6,8,11$ & $1,6,8$ \\
\hline 11 & $1,6,8,11$ & 11 & 11 \\
\hline \multicolumn{4}{|c|}{ Level-6 } \\
\hline Factors & Reachability set $(R)$ & Antecedent set $(C)$ & Intersection $\operatorname{set}(R C)$ \\
\hline 11 & 11 & 11 & 11 \\
\hline
\end{tabular}

Notes: $\mathrm{L} 1=\{2,12\} ; \mathrm{L} 2=\{3,9,10\} ; \mathrm{L} 3=\{5\} ; \mathrm{L} 4=\{4,7\} ; \mathrm{L} 5=\{1,6,8\} ; \mathrm{L} 6=\{11\}$. 
Here $\mathrm{L}_{\mathrm{i}}$ represents $i^{\text {th }}$ level of multilevel hierarchy ISM-based model as shown in Figure 2. The numbers inside the bracket indicate the respective enablers for our study.

\subsection{Formation of digraph or driving power-dependence diagram}

The driving power of an enabler is defined as the total number of enablers, which it may lead to and dependence is the total number of enablers that are responsible for this enabler. Based on the driving power and dependence as obtained from Table 6, the graph plotted is called a digraph or directed graph as shown in Figure 1. In this digraph, the identified enablers are classified into four clusters, namely, autonomous, dependent, linkage and independent. Autonomous enablers (I) is the first cluster having those enablers that have weak driving power and weak dependence. Under this category 5, 7 enablers are kept. Dependent enablers (II) is the second cluster having those enablers that have weak driving power but strong dependence. In this cluster 2, 3, 9, 10, 12 are identified. Linkage enabler (III) is the third cluster having those enablers that have strong driving power and strong dependence. No enablers are present in this cluster. Independent (driver) enablers (IV) is the fourth cluster having those enablers that have strong driving power and weak dependence. The enablers 1, 4, 6, 8, 11 are identified in this cluster.

Figure 1 Digraph or driving power-dependence

\begin{tabular}{|c|c|c|c|c|c|c|c|c|c|c|c|c|c|}
\hline d & 12 & sfg & & & & & & & & & & & \\
\hline$r$ & 11 & & & & $\mathrm{pms}, \mathrm{sm}$ & & cf & & & & & & \\
\hline i & 10 & & & & & & & & & & & & \\
\hline $\mathrm{v}$ & 9 & & & IV & & & & & & III & & & \\
\hline ' & 8 & & & & & & & & & & & & \\
\hline g & 7 & & & & & & IT & & & & & & \\
\hline & 6 & & & & & AoD & & & & LF & $\mathrm{CW}$ & & \\
\hline$p$ & 5 & & & & & & SoT & & & PS & & & \\
\hline w & 4 & & & & & & & & & & & & \\
\hline e & 3 & & & 1 & & & & & & II & & & \\
\hline$r$ & 2 & & & & & & & & & & & & PA, conn \\
\hline 1 & 1 & & & & & & & & & & & & \\
\hline 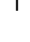 & & 1 & 2 & 3 & 4 & 5 & 6 & 7 & 8 & 9 & 10 & 11 & 12 \\
\hline & & & & & & & Depen & cee $\rightarrow$ & & & & & \\
\hline
\end{tabular}

\subsection{Formation of ISM-based multilevel hierarchy model}

The multilevel hierarchy structural model is formed on the basis of pair wise relationship and the iteration method. 
Figure 2 Multilevel hierarchy structure ISM-based model of the enablers (see online version for colours)

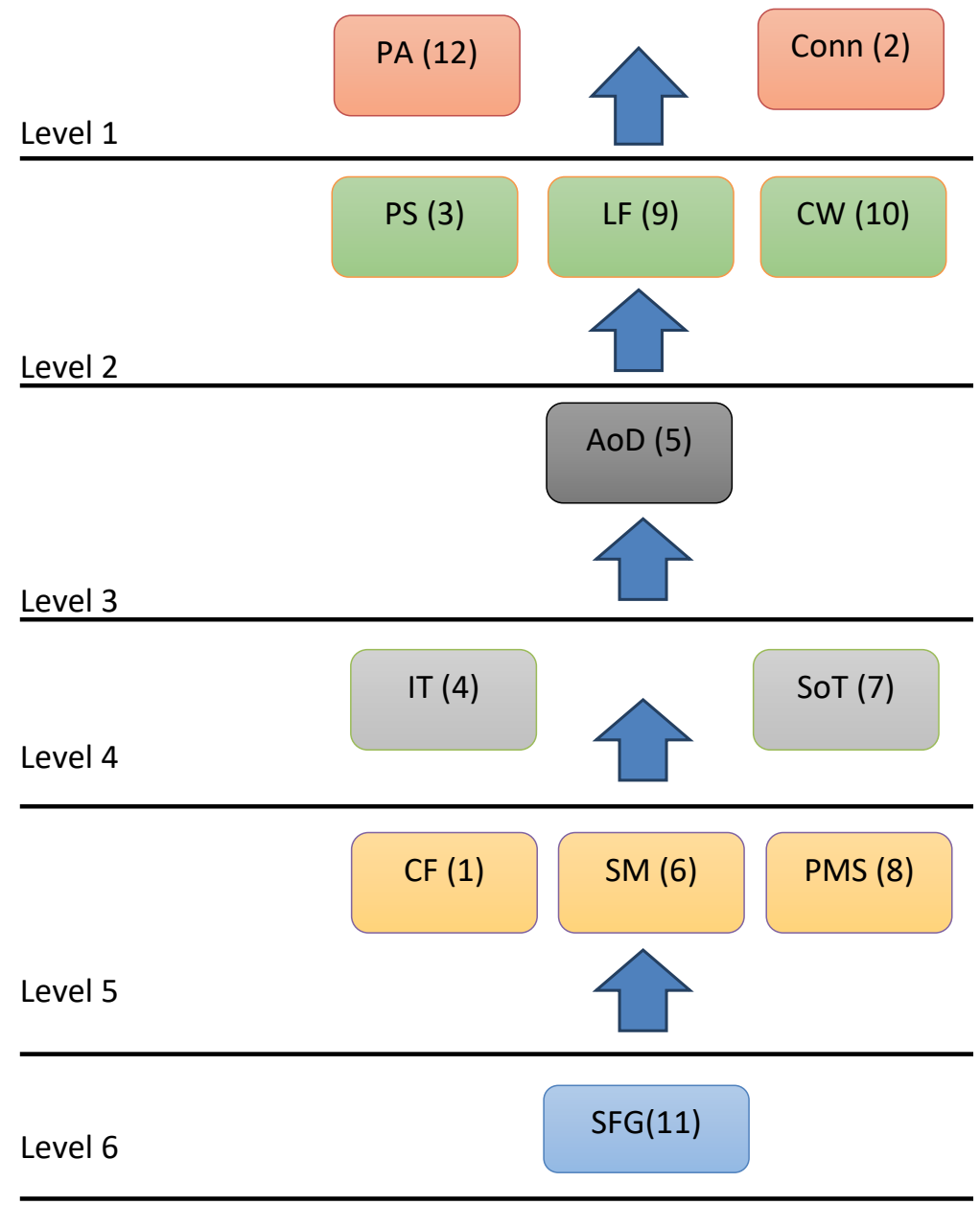

\section{Results and discussion}

Enabler analysis is one way to predict the success rate of IT implementation in telemedicine and to develop a relationship among those enablers. It is very important to know the enablers behind the use of information technology for having an idea to use effectively and efficiently or not, and which one should be given more priorities.

In our recent study, we have observed that the enabler i.e. support from government is most important and fundamental to others due to its higher driving power and low dependence. It has been proved as it is shown in Figure 1. According to experts and staffs, it is recommended that without support from government the effectiveness of the system will not be visible. This enabler is in top level which drives other directly or indirectly. 
As in the global market, computer and information technology advancement is growing rapidly and so also its applications and the government sector are no exception to it. Use of information technology is the one way to bridge the shortage of resources to the customers at large. The present study, on the finding enabler and their interrelation for success in information technology implementation in telemedicine case, can help managers to understand their relative importance, which will facilitate the implementation and improve the success rate by using ISM. The study also represents a multilevel hierarchical model of identified enablers by ISM and a digraph, which shows their driving power and dependence.

\section{References}

Adel, A. and Karim, B. (2013) 'Designing a model for business process orientation using interpretive structural modeling approach (ISM)', African Journal of Business Management, Vol. 7, No. 26, pp.2558-2569.

Agarwal, A., Shankar, R. and Tiwari, M.K. (2006) 'Modeling agility of supply chain', Industrial Marketing Management, Vol. 36, No. 4, pp.443-457.

Attri, R., Grover, S., Dev, N. and Kumar, D. (2012) 'An ISM approach for modelling the enablers in the implementation of total productive maintenance (TPM)', International Journal System Assurance Engineering and Management, DOI: 10.1007/s13198-012-0088-7.

Attri, R., Grover, S., Dev, N. and Kumar, D. (2013) 'An ISM approach for modelling the enablers in the implementation of total productive maintenance (TPM)', International Journal System Assurance Engineering and Management, Vol. 4, p.365, doi: 10.1007/s13198-012-0122-9.

Bolanos, R., Fontela, E., Nenclares, A. and Paster, P. (2005) 'Using interpretive structural modeling in strategic decision making groups', Management Decision, Vol. 43, No. 6, pp.877-895.

Bouwmans, T. (2011) 'Recent advanced statistical background modeling for foreground detection: a systematic survey', Recent Patents Computer Science, Vol. 4, No. 3, pp.147-171.

David, W.M. (1975) 'An introduction to the application of interpretive structural modelling', Proceedings of the IEEE, Vol. 63, No. 3, pp.397-404.

El, H.M.M. and Monir, I.A. (2016) 'A proposed model for improving performance and reducing costs of it through cloud computing of Egyptian business enterprises', International Journal on Cloud Computing: Services and Architecture (IJCCSA), February, Vol. 6, No. 1, pp.1-6, DOI: 10.5121/ijccsa.2016.61011.

Faisal, M.N., Banwat, D.K. and Shankar, R. (2006) 'Supply chain risk mitigation: modeling the enablers', Business Process Management Journal, Vol. 12, No. 4, pp.532-552.

Faisal, M.N., Banwat, D.K. and Shankar, R. (2007) 'Information risks management in supply chain: an assessment and mitigation framework', Journal of Enterprise Information Management, Vol. 20, No. 6, pp.677-699.

George, J.P. and Pramod, V.R. (2014) 'An interpretive structural model (ISM) analysis approach in steel re rolling mills', International Journal of Research in Engineering \& Technology, ISSN(E): 2321-8843, ISSN(P): 2347-4599, April 2014, Vol. 2, No. 4, pp.161-174.

$\mathrm{Hu}$, J., Gao, Z. and Pan, W. (2013) 'Multiangle social network recommendation algorithms and similarity network evaluation', Journal of Applied Mathematics, Vol. 2013, pp.1-8, Article ID 248084, 8pp.

Jayant, A., Azhar, M. and Singh, P. (2014) 'Interpretive structural modeling (ISM) approach: a state of the art literature review', IJRMET, Vol. 5, No. 1, pp.15-21.

Jharkharia, S. and Shankar, R. (2004) 'IT-enablement of supply chains: modelling the enablers', International Journal of Production and Performance Management, Vol. 53, No. 8, pp.700-712. 
Jitesh, T., Arun, K. and Deshmukh, S.G. (2008) 'Interpretive structural modeling (ISM) of IT enablers for Indian manufacturing SMEs', Information Management and Computer Security, Vol. 16, No. 2, pp.113-136.

Kumar, R., Agrawal, R. and Sharma, V. (2013) 'E-applications in Indian agri-food supply chain: relationship among enablers', Global Business Review, Vol. 14, No. 4, pp.711-727.

Mandal, A. and Deshmukh, S.G. (1994) 'Vendor selection using interpretive structural modeling (ISM)', International Journal of Operations and Production Management, Vol. 14, No. 6, pp.52-59.

Qureshi, M.N., Kumar, D. and Kumar, P. (2007) 'Modeling the logistics outsourcing relationships variables to enhance shippers productivity and competitiveness in logistics supply chain', International Journal of Production and Performance Management, Vol. 56, No. 8, pp.689-714.

Raj, T., Attri, R. and Jain, V. (2012) 'Modelling the factor affecting flexibility in FMS', International Journal of Industrial and System Engineering, Vol. 11, No. 4, pp.350-374.

Rajesh, A., Sandeep, G., Nikhil, D. and Deepak, K. (2013) 'An ISM approach for modelling the enablers in the implementation of total productive maintenance (TPM)', Int. J. Syst. Assur. Eng. Manag., Vol. 4, No. 4, pp.313-326.

Ratnam, K.A. and Dominic, P.D.D. (2016) 'Factors associating the IT capability in healthcare services and its perceived transformation impact', Int. J. of Business Information Systems, Vol. 22, No. 1, pp.82-99.

Ravi, V., Shankar, R. and Tiwari, M.K. (2005) 'Productivity improvement of a computer hardware supply chain', International Journal of Production and Performance Measurement, Vol. 54, No. 4, pp.239-255.

Saxena, J.P., Sushil and Vrat, P. (1990) 'The impact of indirect relationships in classification of variables: a MICMAC analysis for energy conservation', System Research, Vol. 7, No. 4, pp.245-253.

Saxena, J.P., Sushil and Vrat, P. (1992) 'Scenario building: a critical study of energy conservation in the Indian cement industry', Technological Forecasting and Social Change, Vol. 41, No. 2, pp.121-146.

Sharma, H.D., Gupta, A.D. and Sushil (1995) 'The objectives of waste management in India: a future inquiry', Technological Forecasting and Social Change, Vol. 48, No. 3, pp.285-309.

Sharma, S., Shandilya, R., Patnaik, S. and Mahapatra, A. (2014) 'Leading NoSQL models for handling Big Data: a brief review', Int. J. of Business Information Systems, Vol. 22, No. 1, pp.1-25.

Sharma, S., Tim, U.S., Wong, J., Gadia, S. and Sharma, S. (2016) 'A brief review on leading Big Data models', Data Science Journal, Vol. 13, No. 4, pp.138-157.

Singh, M.D., Shankar, R., Narain, R. and Agarwal, A. (2003) 'An interpretive structural modeling of knowledge management in engineering industries', Journal of Advances in Management Research, Vol. 1, No. 1, pp.28-40.

Singh, R.K., Garg, S.K., Deshmukh, S.G. and Kumar, M. (2007) 'Modeling of critical success factors for implementation of AMTs', Journal of Modelling in Management, Vol. 2, No. 3, pp.232-250.

Thakkar, J., Deshmukh, S.G., Gupta, A.D. and Shankar, R. (2007) 'Development of score card: an integrated approach of ISM and ANP', International Journal of Production and Performance Management, Vol. 56, No. 1, pp.25-59.

Thakkar, J., Kanda, A., Deshmukh, S.G. (2008) 'Evaluation of buyer supplier relationships using an integrated mathematical approach of interpretive structural modeling (ISM) and graph theoretic approach', Journal of Manufacturing Technology Management, Vol. 19, No. 1, pp.92-124.

Warfield, J. (1976) Social Systems: Planning, Policy and Complexity, John Wiley and Sons, Inc., New York, NY.

Watson R.H. (1978) 'Interpretive structural modeling - a useful tool for technology assessment', Technological Forecasting and Social Change, Vol. 11, No. 2, pp.165-185 [online] http://dx.doi.org/10.1016/0040-1625(78)90028-8. 